\title{
LOS DERECHOS SOCIALES EN EL ENTRAMADO DEL ESTADO SOCIAL
}

SOCIAL RIGHTS IN THE FRAMEWORK OF THE SOCIAL STATE

María Carlota Ucín ${ }^{I}$ ${ }^{\mathrm{I}}$ Erasmus School of Law, Erasmus
University Rotterdam, The Netherlands.
Doutora em Direito. E-mail: ucin@law.
eur.nl

\begin{abstract}
Resumen: La incorporación de los derechos económicos, sociales y culturales (en adelante DESC) en las Constituciones, a partir del llamado "constitucionalismo social" en la segunda mitad del siglo pasado fue paralela al desarrollo del Estado de Bienestar o Social. Esta circunstancia determina algunos de los caracteres propios de estos derechos, su contenido y también, qué es lo que se puede reclamar en su nombre. Es por ello que la adecuada comprensión de los mismos impone su integración dentro del funcionamiento de esta forma estatal, tal como aquí se propone. Se puede afirmar que los DESC son tan solo una cara jurídica de la llamada "cuestión social" y por ello un análisis de los mismos - aun cuando se pretenda estrictamente jurídico - no debería descuidar la visión de aquellas otras dimensiones sociales y sus problemas.
\end{abstract}

Palabras-clave: derechos sociales; constitucionalismo social; estado social.

\begin{abstract}
The incorporation of economic, social and cultural rights (hereinafter ESCR) in the Constitutions, from the so-called "social constitutionalism" in the second half of the last century was parallel to the development of the Welfare or Social State. This circumstance determines some of the characteristics of these rights, their content and also what can be claimed on their behalf. That is why the proper understanding of them imposes their integration into the functioning of this state form, as proposed here. It can be affirmed that ESCR are only one legal face of the so-called "social question" and therefore an analysis of them - even when it is intended strictly legal- should not neglect the vision of those other social dimensions and their problems.
\end{abstract}

Keywords: social rights; social constitutionalism; social state. 


\section{Introducción ${ }^{1}$}

esde esta mirada, los DESC $^{2}$ podrían ser pensados como el resultado de la
adaptación histórica de una misma idea — la de la igual libertad para todos- a necesidades sociales propias de una etapa del desarrollo capitalista, que mostró que con el libre juego de la autonomía privada en el seno del mercado, no se lograba cumplir con las promesas constitucionales para todas las ciudadanas y ciudadanos. ${ }^{3}$ Desde este punto de vista, entonces, no habría diferencia alguna entre ambas categorías de derechos y ambos serían esenciales para lograr la efectiva autonomía de las personas. ${ }^{4}$

Sin embargo, la comprensión de los DESC en el marco del Estado social permite entender sus particularidades, obligando a apartarse de aquella suerte de mainstream doctrinal que propugna la equiparación completa de éstos con los civiles y políticos. Tal contextualización, en cambio, pone de manifiesto la necesidad de elaborar nociones teóricas más precisas para captar a estos derechos. Por ello mismo, la postura doctrinal que procura echar luz sobre las similitudes de estas dos categorías de derechos — disimulando sus diferencias — como forma de fundar su igual valor jurídico resulta insuficiente incluso para los fines de la exigibilidad plena que persigue. $^{5}$

El surgimiento de la preocupación por la "cuestión social" —esto es: el problema de la pobreza, la desigualdad y las cuestiones laborales derivadas de las disfunciones de la sociedad industrial — originó un aumento de las funciones atribuidas al Estado. Comenzaron así a desarrollarse formas de superación de la relación person to person, típica de la asistencia caritativa

1 Esta publicación es parte del proyecto: Affordable access to justice (subproject: From public to private funding), número de proyecto VI.C.191.082 del programa Vici de investigación que es financiado por el Consejo Neerlandés de Investigación (NWO).

2 En adelante habré de utilizar indistintamente los términos: Estado Social o de Bienestar, dejando deliberadamente de lado la denominación de Estado Providencia. En este sentido, señala Castel que esta última denominación es problemática, en primer lugar, porque parece postular una relación cara a cara entre un Estado benefactor y los beneficiarios, receptáculos pasivos de sus dones. Sin embargo, esta interpretación del rol del Estado social no da cuenta de la posición de tercero que ocupa el Estado entre los grupos de intereses opuestos. Ello así por cuanto el Estado administra el antagonismo y el conflicto, al menos tanto como pacifica. Además, esta expresión fue inventada por los detractores de la intervención pública, para denunciar esa pretendida servidumbre, siendo así una construcción ideológica montada por los adversarios de la intervención del Estado. En este sentido, esta denominación echa menos luz que oscuridad y prejuzga a la vez, sobre los modos de intervención del Estado. Las denominaciones propuestas en su lugar, resultan en tal sentido neutrales y se dirigen a identificar un Estado que se encarga de la movilización de una parte de los recursos de la nación para asegurar su cohesión interna. Castel, Robert, La metamorfosis de la cuestión social. Una crónica del salariado, Paidós, Buenos Aires, 1997, pp281-2.

3 Así como el derecho civil liberal significó la emancipación del poder premoderno y de ciertas relaciones de dominación, los subsiguientes estadíos de juridificación siguieron el mismo sentido de evolución, garantizando el incremento de la libertad frente a las relaciones modernas de poder y dependencia emergentes de la era capitalista. Véase: Habermas, Jürgen, Law as Medium and Law as Institution, en: Teubner, Gunther (Ed.), Dilemmas of Law in the Welfare State, Walter de Gruyter, Berlin, New York, 1986, pp 203-220.

$4 \mathrm{Y}$ es en este sentido que debe ser interpretada la doctrina de la indivisibilidad e interdependencia de los derechos humanos. Ello así, por cuanto ambas categorías resultan coadyuvantes para el logro del reconocimiento de la dignidad de las personas y el ejercicio de la autonomía. Como es sabido, el expreso reconocimiento de la indivisibilidad de los derechos humanos surgió en la Primera Conferencia Mundial de Derechos Humanos de Teherán de 1968, del Acta Final de Helsinki de 1975 y finalmente, de la Resolución 32/130 de la Asamblea General de Naciones Unidas (16/12/1977).

5 Profundizo este argumento en: Juicio a la desigualdad. La defensa de los derechos sociales a través del proceso, Marcial Pons, Madrid, 2021. 
antecedente, introduciendo prácticas colectivas de atención de la pobreza, las que —a su vezdaban cuenta de que la miseria era un efecto de la industrialización y presentaba rasgos masivos que no podían ser reducidos a una suma de debilidades individuales. ${ }^{6}$

Si bien Estado de Bienestar adquiere su configuración particular en la segunda mitad del siglo pasado, ${ }^{7}$ sus antecedentes se remontan a las diversas respuestas dadas por los países al problema del pauperismo derivado del desarrollo industrial. ${ }^{8}$ Esta forma estatal, como fórmula pacificadora en las sociedades de capitalismo avanzado, apareció creando instrumentos de socialización de las condiciones de producción, velando por la correspondencia entre los objetivos económicos, políticos y sociales. ${ }^{9}$

La misión básica de esta nueva configuración del Estado se definió a partir de la garantía de la seguridad social de sus ciudadanos, mediante transferencias monetarias, servicios, infraestructura física y políticas reguladoras en las áreas de salud, educación, vivienda, seguro social, asistencia social individual y familiar y protección laboral. Sin embargo, la seguridad in $s e$, no es un objetivo privativo de esta nueva forma de Estado, sino que también lo era del Estado liberal que le precedió. La diferencia radica en que, en este último, la seguridad se buscaba a partir del principio de legalidad, como forma de limitar el obrar estatal, asegurando así el goce de la vida y la propiedad de los ciudadanos. El objeto de dicha legalidad era la proscripción de las interferencias arbitrarias sobre la esfera protegida de los individuos. En cambio, la seguridad social y el bienestar que luego se procura asegurar a ciudadanas y ciudadanos, sólo pueden lograrse a través de la intervención positiva del Estado. Y esta acción se debe institucionalizar a través de acciones legales positivas y títulos de derechos otorgados a categorias de personas que poseen ciertas condiciones, las cuales se reconocen como necesitadas de regulación pública, transferencias o servicios. ${ }^{10}$

6 Castel, Robert, La metamorfosis de la cuestión social..., cit., p. 249, 265.

7 Entre los factores que explican el desarrollo del Estado de Bienestar en el siglo XX se pueden referir: i) el warfare, ii) la transformación de la actitud hacia la pobreza que hizo que las leyes anteriores de pobreza no pudieran ser más aplicables en la sociedad democrática, iii) las investigaciones sobre contingencias sociales y la posibilidad de encauzarlas a través de políticas públicas, iv) la asociación entre desempleo y políticas de bienestar, v) el desarrollo de filosofía y prácticas del Estado de Bienestar incluso dentro del capitalismo y vi) la influencia de la clase trabajadora en la legislación social. Además, la fórmula de paz con la que se logró mitigar los conflictos de clase ha sido expuesta como consistente en dos pilares: i) las obligaciones de promoción asistencial a cargo del Estado y ii) el reconocimiento formal a las Uniones de Trabajadores en las negociaciones colectivas y en la formación de políticas públicas. Briggs, Asa, The Welfare State in historical perspective, European Journal of Sociology / Archives Européennes de Sociologie, Volume 2 , Issue 2, December 1961 , pp. 221 - 258 y Offe, Claus, Some contradictions of the modern Welfare State, en Contradictions of the Welfare State, Contemporary politics, London, 1984 (pp 147-161) p.147. Por lo demás, si bien es cierto que no hay un único modelo de Estado de Bienestar, sino tantas variantes como países lo hayan puesto en vigencia, aquí habré de referirme de manera genérica a su forma típica. En punto a los matices diferenciales, resulta aceptada la categorización de EspingAndersen quien distingue tres categorías de Estados de Bienestar: el "Liberal" (orientado hacia el mercado, como el angloamericano), "el conservador" (propio de las Democracias Cristianas de la Europa continental) y el "nórdico" (de orientación socialdemócrata). Al que nosotros podríamos agregar el "latinoamericano" (con su insidiosa tendencia al populismo). Esping-Andersen, Gøsta, The three worlds of welfare capitalism, Cambridge: Polity Press, pp 9-54, 1990.

8 Se han referido como antecedentes del Estado de Bienestar a la legislación social inglesa de los siglos XIX y XX. Véase: Briggs, Asa, The Welfare State in historical perspective, cit.

9 Castel, Robert, La metamorfosis de la cuestión social..., cit., p 382

10 Offe, Claus, Un diseño no productivista para las políticas sociales, en Contra la exclusión. La propuesta del ingreso ciudadano, Miño y Dávila Editores, 2 edición, Buenos Aires, 2004, pp 80-105. 
La acción de estos componentes: categorías, condiciones y titulos de derechos son las que se resumen en el establecimiento de acciones positivas de parte del Estado para lograr el bienestar de sus ciudadanos. Y como señala Offe, existe una importante diferencia lógica entre ambas formas de Estado, el liberal y el de bienestar. Así, mientras que la inacción o el principio de restricción a la acción es siempre operativamente preciso, la acción o el principio del compromiso de actuar positivamente plantean cuestiones de "cuánto", "qué tipo de acciones" y en "beneficio de qué categorías" (y a expensas de quién) se requiere para alcanzar efectivamente tales objetivos sociales. ${ }^{11}$

Esta transformación del Estado y su mayor intervención en la escena político-económica trajo aparejadas innumerables modificaciones en el plano normativo y también conceptual. Estos desarrollos, tal como aquí se verá, muchas veces han ido a la zaga de los acontecimientos. El reconocimiento de derechos sociales pero también la elaboración de políticas públicas para resolver los problemas sociales antes analizados, impactaron sobre los conceptos teóricos tales como el de derecho subjetivo, pero también sobre las formas previstas para controlar la legalidad de la Administración en el Estado liberal, reflejando sus cambios sobre el modo de operar del Derecho constitucional. Estas modificaciones vinieron a desbordar el funcionamiento de las categorías clásicas del Derecho decimonónico.

Además de estas cuestiones, se presentan otras que Habermas vincula a la insuficiencia del paradigma del Estado de Bienestar para conciliar la autonomía privada con la autonomía pública de los ciudadanos. Desde el planteamiento de este último problema, sugiere este autor algunas formas de superar las deficiencias del Estado benefactor, ganando — a la par - en legitimidad para su funcionamiento. A continuación, entonces, se expondrá someramente cómo el Estado social interviene en el mercado para poder dar respuesta a los seńalados problemas sociales.

\section{Los DESC en el entramado el Estado social}

El Estado de bienestar emplea deliberadamente su poder, a través de la política y la Administración, para modificar el juego de las fuerzas del mercado en tres direcciones: i) garantizando a los individuos y sus familias un mínimo de ingreso, independientemente del valor de intercambio de sus trabajos o propiedades; ii) estrechando los alcances de la inseguridad, al habilitar a los individuos y sus familias a la protección social frente a contingencias tales como la enfermedad, el desempleo, la edad avanzada, que de otro modo generarían crisis familiares y iii) asegurando a todos los ciudadanos los mejores estándares posibles en relación a ciertos servicios acordados. ${ }^{12}$

Para ello, el Estado persigue cambios sociales y económicos en pos del aseguramiento de dichas condiciones de vida elementales para toda la población. En punto a los primeros, se puede mencionar los mayores alcances dados a la protección de la Seguridad Social y el aseguramiento de la igualdad de oportunidades. También, la asunción del problema de la abolición de la pobreza, interviniendo para ello en el proceso económico y las tareas sustitutivas en caso de calamidades sociales o de recesión. ${ }^{13}$

11 Ibidem, p82.

12 Briggs, Asa, The Welfare State in historical perspective, cit. pp 221-258.

13 Grimm, D., Constitucionalismo y derechos fundamentales, Editorial Trotta, Madrid, 2006, p 188. 
Estas nuevas formas de intervención estatal se canalizan generalmente a través del diseño de políticas públicas. Las mismas se configuran como programas concretos de acción, estrategias de intervención basadas en las mejores técnicas para resolver problemas públicos, llevadas a cabo por los actores autorizados por el poder estatal. ${ }^{14}$ Estas acciones, racionales y sistemáticas, implican la atención, intervención y solución de problemas de interés general en áreas tales como el bienestar, la salud, la educación, la seguridad, la cultura, entre otros. ${ }^{15} \mathrm{~A}$ su vez, resultan de un proceso de mediación social que procura tomar a su cargo los desajustes que pueden ocurrir entre un sector y otros, o aun entre un sector determinado y la sociedad global, tratando de dar respuesta a problemas sociales concretos. ${ }^{16}$

Pero esta forma de intervención no debe ser interpretada de modo aislado sino que debe ser comprendida en su real dimensión. Se trata de un cambio de paradigma, de una mutación de la comprensión que la sociedad hace acerca de su propio funcionamiento. En este sentido, la misma ya no se comprende como una integración de situaciones individuales homogéneas, tal como era interpretada desde la mirada del paradigma del Derecho privado. Esta última concepción estaba configurada a la medida de la autonomía de los sujetos jurídicos, que en su papel de participantes del mercado habrían de buscar su bienestar a través de la acción racional aplicada a la consecución de sus fines privados. ${ }^{17}$

En cambio, con el nuevo paradigma se asume que la sociedad se encuentra compuesta por grupos sociales, cuyos intereses y necesidades particulares entran en tensión permanente. Así, a partir del llamado proceso de sectorización, la sociedad comienza a ser vista como la integración de grupos sociales con intereses en tensión y cuyo tratamiento particularizado habrá de redundar además en el beneficio de los integrantes de dichos grupos. ${ }^{18}$ Aparecen entonces las categorizaciones específicas - tal como por ejemplo las categorías de productor, consumidor, nińos, mujeres, discapacitados, adultos mayores, inquilinos, propietarios, entre otras - para la regulación de políticas públicas concretas e incluso para el ejercicio clásico del poder de policía. A partir de esto, también el Derecho privado habrá de recoger estas categorías para la regulación y reconocimiento de derechos. ${ }^{19}$

14 Valenti Nigrini, G. - Flores Llanos, U., Ciencias sociales y politicas públicas, en Revista Mexicana de Sociología, Vol. 17, Dic. 2009, pp 167-191 (pp 174-175) y Muller, Pierre, Génesis y fundamento del análisis de politicas públicas, INNOVAR, Revista de Ciencias Administrativas y Sociales, № 11, Enero - Junio de 1998, pp99-109 (p 100).

15 Valenti Nigrini y Flores Llanos, cit., p177.

16 Muller, Pierre, Génesis y fundamento del análisis de politicas públicas, cit. p107.

17 Habermas, J., Facticidad y Validez. Sobre el derecho y el Estado democrático de derecho en términos de teoría del discurso, $4^{\circ}$ Edición, Trotta, Madrid, 2005, p 483.

18 Con el surgimiento del asalariado y el debilitamiento de las solidaridades locales se desarrolla una nueva forma de vínculo social. El Estado de Bienestar, entonces propone una respuesta a la terminación del orden territorial, proporcionando a cada grupo social "no territorial" un lugar y una protección mínima en la sociedad. Se da así, el paso de la asistencia que pertenece al orden del territorio, hacia la técnica aseguradora que tiene que ver con la sectorialidad. El seguro social, marca la transición hacia una protección social organizada sobre una base profesional. Lo social, como sector específico, será así objeto de políticas públicas adaptadas. La consecuencia de ello será que cualquier sociedad sectorial será confrontada con un grave problema de cohesión social. Según Muller, una sociedad que no encuentre los medios para manejar los antagonismos intersectoriales por ejemplo, a través de las políticas públicas, se encuentra amenazada de desintegración. Muller, Pierre, Génesis y fundamento del análisis de políticas públicas, cit. pp104-105.

19 El creciente reconocimiento de los derechos de los consumidores en el marco del Derecho Privado, sin una ruptura total con la lógica de la contratación individual (aunque ahora masiva) da cuenta de este fenómeno. 
Para dar respuesta a esta nueva mirada sobre el problema social, asumiendo a su vez, la insuficiencia de los mecanismos de mercado para dar respuesta a sus propios fallos se pensó que la solución vendría dada a partir de la materialización del Derecho. La misma resulta de la verificación de la circunstancia de que la libertad jurídica, como permisión abstracta de realizar u omitir algo, carece de valor sin libertad fáctica, sin la posibilidad efectiva de elegir entre lo permitido. $^{20}$

El objetivo de las intervenciones estatales, concretadas en este sentido socializador del Derecho, se resume en la compensación de la asimétrica distribución del poder. Este fenómeno, también se patentizó en la incorporación de derechos sociales en las Constituciones, dando origen al Constitucionalismo social. ${ }^{21}$ Estos nuevos derechos con contenido material fundan pretensiones de recibir prestaciones que fomenten una distribución más justa de la riqueza socialmente producida y una protección más eficaz frente a los llamados "riesgos sociales".

La nueva comprensión de fondo asume, de un lado, la imagen de una sociedad compuesta de diversos ámbitos de acción funcionalmente especificados y de otro, mantiene la expectativa de que esas contingencias puedan ser domadas normativamente, usando el poder administrativo, mediante operaciones de control sistémico. ${ }^{22}$ Una concepción sociológica como esta permite comprender a la sociedad como una integración de grupos solidarios y antagónicos. Entonces, la identificación de los derechos de cada uno pasa a ser asociada con los intereses colectivos de aquellos grupos de los que son parte. Estos intereses colectivos tienden así a absorber los intereses individuales, cuya existencia no es sino la individualización de los primeros. Así es que se asume que no existe un único Interés Público o colectivo, como principio totalizador. En cambio, dicho Interés Público, surge del reconocimiento y respeto de todos ellos. ${ }^{23}$

Resulta lógico pensar que el Estado, en su misión de lograr el cambio de ciertas estructuras sociales y tendiendo a garantizar un mayor bienestar o una mayor protección para los sectores más vulnerables de la sociedad, habrá de encontrarse con dificultades teóricas y prácticas. En este sentido, parece plausible aceptar el aserto de que cuando las funciones estatales exceden el mero mantenimiento del statu quo, pueden aparecer inagotables, pues la meta de alcanzar un cierto

20 La "materialización” del Derecho terminó de imponerse con todo su alcance con el Estado Social de posguerra. Este cambio social del Derecho o giro social recubrió, desplazó y finalmente relevó al modelo liberal. Este proceso disolvía la unidad clásica y la articulación sistemática de que se entendía como el único orden jurídico racional, lo que fue percibido como una "crisis" del Derecho. Habermas, Facticidad y Validez..., cit., p 471 y 485.

21 La aparición de este rasgo social en el constitucionalismo latinoamericano, se evidencia también a partir de la segunda mitad del siglo XX, o quizás antes, con el antecedente de la Constitución mexicana de 1917. Lo cierto es que la mutación en el rol del Estado a partir de 1930 — como reflejo de la crisis económica mundial y la ampliación del sufragio que permitió el acceso de grandes masas trabajadoras a la política- llevaron casi de manera inevitable al tratamiento de la cuestión social y el reconocimiento de derechos sociales. En dicho marco, como lo sostiene Gargarella, las Constituciones latinoamericanas, comenzaron, una tras otra, a anexar a la vieja matriz liberal-conservadora (sin suprimirla) nuevas preocupaciones sociales. Ello arrojó, como resultante, un constitucionalismo "social" en materia de derechos, pero demasiado conservador, en materia de organización del poder. Gargarella, Roberto, La sala de máquinas de la Constitución. Dos siglos de constitucionalismo en América Latina (1810-2010), Katz, Buenos Aires, 2014, pp 199-203.

El desarrollo de estas reformas en el plano normativo importa una necesaria revisión tanto de las categorías con que se puedan aprehender los derechos fundamentales, cuanto también una reconsideración de las formas de control de constitucionalidad. Temas éstos sobre los que se volverá más adelante.

22 Habermas, Facticidad y Validez..., cit., p 487

23 Ewald, François, A concept of Social Law en Dilemmas of Law in the Welfare State, Teubner, Gunther (Ed.), Walter de Gruyter, Berlin, New York, 1986, pp 40, 52-3. 
grado de justicia social resulta también infinita. Debido a ello, se han analizado las rupturas o desbordes que este modelo estatal produce en las previsiones clásicas del constitucionalismo decimonónico. ${ }^{24}$

Aquí, habré de centrarme en particular en los desbordes conceptuales derivados de este cambio del funcionamiento estatal. Como se mostrará a continuación, las crecientes funciones públicas resultan difícilmente captadas por el límite que el Estado liberal establecía al obrar estatal. Mantener al Estado limitado, fuera del margen protegido de la sociedad civil, es cosa bien diversa de controlarlo cuando se le ha requerido la intervención en el funcionamiento de dicha sociedad. Así, entonces, se habla de la insuficiencia del principio de legalidad para captar estos límites. Esto habrá de redundar como se demostrará, en la forma del control judicial que se pueda realizar del obrar estatal en estas áreas.

\section{La insuficiencia del principio de legalidad para captar el funcionamiento del obrar estatal}

Con el crecimiento estatal se producen ciertos desbordes en la lógica del Derecho Constitucional clásico. Estas cuestiones, por su parte, no han tenido suficiente consideración en el plano teórico-conceptual. Muchas veces esto se ha debido a los desacuerdos ideológicos que han bloqueado la posibilidad de avanzar sobre la solución de tales problemas. En el caso de la incorporación de los derechos sociales a las Constituciones latinoamericanas, esto se muestra con cierta evidencia en las tensiones internas que derivan de la "mezcla" de sistemas de protección de derechos amplios y formas de organización del poder más conservadoras. ${ }^{25}$

Además, la señalada preocupación por alcanzar un cierto nivel de justicia social llevó a que el Estado asumiera ciertas metas materiales. Para ello, debió desempeñar nuevos roles de planificación, dirección y ejecución de planes de largo plazo, desencajando de las funciones y de los modos de control previstos en la forma liberal de la Constitución. Como ya se ha expuesto, la finalidad de la Constitución liberal fue la de preservar el espacio de libertad propio de la sociedad y el mercado, este último como espacio de asignación libre de recursos. Entonces, se debía regular la actuación del Estado para evitar injerencias arbitrarias. Así es que la garantía de la legalidad fue pensada para controlar los abusos de poder.

Debe considerarse que, en el marco de una clara separación entre el Estado y la sociedad, como la propuesta por el Constitucionalismo liberal, los derechos fundamentales servían de vallas para frenar el avance estatal, pero especialmente como escudos protectores de una esfera de autonomía reservada a los particulares. En tal sentido, aun cuando el obrar de la Administración fuera positivo, el principio de legalidad y luego el eventual control judicial del obrar administrativo, mantenían al Estado dentro de sus límites. Los espacios de la sociedad y del Estado estaban claramente demarcados, así como también los modos de asegurarlos a partir del referido control de la legalidad.

24 Grimm, D., Constitucionalismo y derechos fundamentales, Editorial Trotta, Madrid, 2006, pp 39-41.

25 Es lo que Gargarella identifica como "contradicciones inter-seccionales" en una Constitución que afirma compromisos contradictorios entre la sección de derechos y la sección de organización del poder. Lo que por ejemplo se da por la incorporación de derechos sociales, sin la adecuada modificación de la organización concentrada del poder. Gargarella, Roberto, La sala de máquinas de la Constitución... cit. pp 297-303. 
Sin embargo, ésta no puede ser suficiente cuando se espera del Estado un obrar positivo. ${ }^{26}$ Las nuevas funciones estatales no sólo van dirigidas a obrar en dicho espacio que le ha fijado claramente la sociedad. Muchas veces, para poder desempeñar las funciones que se le encomiendan, el Estado habrá de intervenir también en la esfera social y económica. La referida actividad de mediación y planificación a través del diseño y puesta en funcionamiento de políticas públicas específicas, para la coordinación de los sectores con intereses contrapuestos lleva — como es lógico pensar- a exorbitar aquella mirada limitante del obrar estatal.

Es por ello que se ha podido decir que el obrar estatal dejaría de estar sujeto al control de legalidad clásico, con el riesgo de no poder controlarse la discrecionalidad de la Administración. Ello así pues el legislador del Estado social delegó en la Administración tareas de planificación, configuración y regulación de programas sociales. Esta Administración, especializada en prestaciones y subsidios, se encarga ahora de las necesidades de sus clientes, poniendo a punto infraestructuras necesarias y planificando la evitación de riesgos. Se dedica a tareas de regulación política orientadas al futuro y sus intervenciones pueden afectar las relaciones de los ciudadanos y de los grupos sociales entre sí. Para lo cual, la forma clásica de la ley como límite de su obrar resulta simplemente inaplicable. ${ }^{27}$

Y si bien, podría pensarse en la adaptación o flexibilización de esta noción — para hacerla extensiva a programas de gobierno no estrictamente legales - es cierto que con ello no se alcanza la solución del problema. En primer lugar, porque los problemas sociales o la consecución de ciertos fines no resultan fácilmente mensurables a los efectos de un control normativo. No sólo resulta efectivamente difícil provocar cambios sociales a través del Derecho sino que, además, tales cambios o metas a alcanzar resultan casi inconmensurables. ${ }^{28}$ Esta dificultad de objetivar los progresos es la que dificulta también el ejercicio de un control de cumplimiento de dichas metas a partir de las herramientas clásicas del control judicial.

Así, por ejemplo, puede pensarse en la estructura de los derechos sociales. Ellos recogen algunas de las señaladas dificultades e indeterminaciones. Entonces, no sólo resulta difícil pensar que con el mero reconocimiento constitucional o la puesta en marcha de políticas sociales pueda alcanzarse aquello que prometen. También se debe aceptar que la evaluación de su cumplimiento no será algo tan lineal como la injerencia arbitraria sobre espacios de libertad en el funcionamiento

26 La fuerza reguladora de la Constitución se hundió como consecuencia de la reorganización del orden estatal liberal en el modelo del Estado de Bienestar. Ello se puede relacionar con el tipo de actividad que desarrolla esta nueva forma de Estado: de planificación, dirección y ejecución. Estas nuevas tareas son de por sí de intervención y exceden en alguna medida el principio de legalidad de la Administración concebido como límite a la acción. Al actuar en un espacio ajurídico, la Administración rechaza también su control judicial. Lo que se ha intentado morigerar extendiendo los conceptos de intervención y sujeción a la ley. Pero esta salida tiene sus limitaciones, en primer lugar, porque los problemas materiales no pueden resolverse totalmente en el plano normativo y, en segundo lugar, porque la actividad material del Estado es prospectiva y abarcadora. En este sentido, resulta tan compleja que no puede anticiparse intelectualmente a los efectos de regularla previamente. Es por eso que donde el objetivo es alcanzar ciertas metas, las exigencias del control clásico de la Administración funcionan limitadamente. Véase Grimm, Dieter, Constitucionalismo y derechos fundamentales, cit., pp73-4.

27 Habermas, J., Facticidad y validez..., cit., p 516.

28 Se habla de la inadecuación de la coacción y la sanción como modo de imponer conductas para poder producir modificaciones materiales en la esfera social y económica donde se gobierna. Además, resulta plausible pensar que aun cuando la Constitución fijara un nivel determinado de satisfacción de un derecho, o el Estado se comprometiera a ello mediante una ley, si las condiciones fácticas determinan la imposibilidad de cumplirlo, sería fútil desconocer que estamos allí ante un confín del Derecho y sus propias posibilidades. Grimm, Dieter, Constitucionalismo y derechos fundamentales, cit., pp 193-6 y 170-173. 
clásico de los derechos. El contenido de los DESC, que fija un estado de cosas a alcanzar en mayor o menor grado, impone herramientas nuevas y adecuadas para su control.

Porúltimo, cabe referirquelas inadecuaciones surgen también a partir dela programaticidad de estos derechos. ${ }^{29}$ De ella se deriva la necesidad de que, para dar cumplimiento a los derechos sociales, se pongan en marcha medidas de acción concreta como las antes referidas, en programas que a su vez no estarán necesariamente sujetos al control de legalidad clásico. Sin embargo, ¿qué hacer cuando el Estado no hace nada para dar vigencia a estos derechos? En términos estrictos y dentro de la lógica del control de legalidad de la administración clásica, sin dicha ley que fije la "legalidad administrativa", se volvería difícil juzgar el obrar administrativo. La abstención de obrar o un obrar que crece en espacios discrecionales creados a través de "programas sociales" sin forma de ley, desborda el control clásico de legalidad. Pero, además, sin dicha ley el ciudadano no podría reclamar nada judicialmente porque la Administración (i.e. el Estado) no habría violado los límites de la legalidad, no se configuraría en el caso abuso estatal alguno. ${ }^{30}$

Éste es el verdadero sentido técnico y problemático de la programaticidad de los derechos sociales. Sin embargo, no debe pensarse que esta característica pueda obstar al control, no ya de legalidad del obrar estatal entonces, sino de constitucionalidad o de convencionalidad. Al contrario, de lo que se trata es de dejar planteados los límites de las herramientas existentes y sus problemas para poder desentrańar cuáles han de ser las modificaciones que deben ser introducidas para controlar las nuevas funciones estatales y evaluar la razonabilidad de sus intervenciones.

En el cumplimiento de los objetivos constitucionales caben numerosas opciones y le corresponde a la política la determinación de prioridades y la selección de los recursos para lograr las metas constitucionales. He aquí, la importancia de desarrollar parámetros objetivos para la medición del cumplimiento de las obligaciones por parte de los Estados. En este sentido, el control de proporcionalidad es el que resulta más adecuado al control de la vigencia de los derechos sociales concebidos como principios constitucionales (i.e. mandatos de optimización), así como también resulta importante poder desarrollar estándares normativos que fijen cotas para medir el progreso en el cumplimiento estatal. ${ }^{31}$

29 Si bien rechazo la idea de que la programaticidad sea un óbice para el reclamo judicial directo de los DESC, entiendo que hay un aspecto de aquélla que no puede ser desdeńado. La programaticidad alude, en cambio, a que los derechos para ser efectivamente puestos en vigencia requieren de parte del Estado la elaboración de programas concretos, que equilibren intereses y asignen equitativamente recursos. De ello no se sigue que ante la omisión estatal, la programaticidad pueda operar como defensa a favor del Estado.

30 En un sentido afín al presentado en el texto, Ferrajoli indica que las garantías —en tanto técnicas previstas por el ordenamiento jurídico para reducir la distancia estructural entre normatividad y efectividad — posibilitan la máxima eficacia de los derechos fundamentales en coherencia con su estipulación constitucional. Así, distingue las "garantías liberales" de las "sociales". Las primeras —al orientarse a la tutela de los derechos de libertadconsisten especialmente en técnicas de invalidación o anulación de los actos prohibidos que las violan. En cambio, las garantías sociales — orientada a la tutela de los derechos sociales-consisten en técnicas de coerción o sanción contra la omisión de las medidas obligatorias que las satisfacen. En: Ferrajoli, Luigi, Derechos y garantías. La ley del más débil, $7^{\circ}$ edición, Trotta, Madrid, 2010, p 25.

31 Así, aun cuando exista una política pública establecida a partir de leyes que enmarquen el obrar del poder administrador, puede suceder que la garantía de la "reserva de ley" devengue vacua. Es decir, puede ser que la propia ley, al establecer determinado sistema de redistribución, priorizando un derecho sobre otros, afecte a otros grupos con posiciones enfrentadas en materia de derechos fundamentales. Aquí es dable destacar la importancia del principio de proporcionalidad (junto con el ejercicio argumental de la ponderación) para dar solución a estas tensiones. A través de este esquema argumental, los jueces pueden controlar la propia ley que justifica el obrar administrativo (legal pero eventualmente inconstitucional). Este examen, a partir del control de la necesidad, idoneidad y proporcionalidad stricto sensu, verifica que no haya una restricción irrazonable de 


\section{La insuficiencia de la noción de derecho subjetivo para la comprensión de los derechos sociales}

El reconocimiento de derechos sociales pone de manifiesto también la inadecuación de las categorías teóricas pensadas para un Estado abstencionista y la necesidad de una nueva comprensión de la sociedad. En el marco de la comprensión liberal, se ve a la sociedad como una reunión de individuos autónomos y para ello resulta suficiente la figura de los derechos subjetivos. Los mismos funcionan perfectamente para entender y conceptualizar las contrataciones libres que realizan las personas en el seno de una sociedad que delega la asignación de recursos en el mercado.

En la visión del Estado social subyace una consideración diversa de la sociedad, caracterizada por la existencia de categorías de sujetos con intereses afines que pueden entrar en tensión con los intereses de otros grupos. Además, los DESC imponen funciones de redistribución al Estado. En consecuencia, las obligaciones son consideradas como el vínculo entre individuos pero siempre en el contexto de la sociedad de la que son parte, la que a su vez juega un papel de intermediación y redistribución. ${ }^{32}$

El Derecho social, como modo especial de regulación de las diferencias, es un instrumento de intervención que sirve para compensar y corregir iniquidades. Por eso, es un Derecho de preferencias y no de reciprocidades, es una legislación de discriminaciones positivas. Su novedad no reside tanto en el contenido de los derechos, sino en llevar el conflicto al interior de la legislación, imponiendo para su aplicación la forma de los acuerdos o la ponderación de los intereses en tensión. ${ }^{33}$

Es por todo esto que la categoría del derecho subjetivo muestra tantas dificultades para comprender los alcances y el funcionamiento de los DESC. Esta dificultad ha sido el fundamento de quienes han negado a estos derechos toda su fuerza normativa. Sin embargo, esta imposibilidad de casar los derechos en dicho molde lejos está de permitir la conclusión más obvia o rápida. De ello no se sigue que sean derechos imperfectos. Lo imperfecto, acaso, se ubique en el desarrollo deficiente de la teoría jurídica para dar respuesta a este irreversible cambio de paradigma.

La salida parece encontrarse, en cambio, en la comprensión de los derechos fundamentales como mandatos de optimización o principios. ${ }^{34}$ Esta revisión de la estructura y funcionamiento de los derechos sociales, junto con los correlativos cambios en el funcionamiento estatal, son los que habrán de incidir en la forma que adopte el control judicial a su respecto. ${ }^{35}$

los derechos fundamentales afectados y que se haya logrado, del modo más adecuado, el compromiso de las posiciones en tensión. Todo esto, sin perjuicio de la necesidad de adecuar sus postulados para la revisión de los supuestos de omisión estatal para el caso de los DESC. Para una propuesta específica aplicada a los DESC, remito a lo dicho en: Juicio a la desigualdad. La defensa de los derechos sociales a través del proceso, Marcial Pons, Madrid, 2021.

32 Ewald, François, A concept of social Law, cit., p 41.

33 Ibidem, pp 46 y 48.

34 Sin embargo, se alerta también que la ganancia no es absoluta en este sentido. De hecho, señala Grimm que, al apartarse de la lógica de los derechos subjetivos, se pierde la posibilidad de un mejor control estatal. Cuando se abandona la idea de la prohibición y se adopta la noción de los "objetivos" que deben ser alcanzados, se pierde en certeza y en la posibilidad de medir los apartamientos de tales prescripciones. En Constitucionalismo y derechos fundamentales, cit., pp205-209.

35 Véase: Juicio a la desigualdad. La defensa de los derechos sociales a través del proceso, cit. 


\section{Problemas de legitimidad del Estado social}

Una de las críticas que se han hecho al Estado social ha estado asociada a la "insensibilidad" de las crecientes burocracias estatales frente a las restricciones que su actuación suponía para la autodeterminación individual de sus clientes. Cierto es que tal debilidad resultaba en todo caso simétrica a la "ceguera social" del Derecho formal burgués. ${ }^{36}$ Por lo demás, esta falsa oposición de dos modelos — como si fueran las únicas alternativas posibles— es la que permitió cierta aporía en las discusiones, donde las fallas del Estado de Bienestar parecían sugerir el retorno a un modelo anterior. Sin embargo, tal retorno al Estado liberal resulta en verdad impensable, no sólo porque no se dan las condiciones materiales que lo hicieron históricamente posible en una etapa de surgimiento del industrialismo, sino porque además ha cambiado la manera en que la sociedad analiza y comprende sus problemas sociales, cada vez más complejos.

Ambos paradigmas, según Habermas, comparten la imagen productivista de la sociedad, centrada en una economía articulada en términos de capitalismo industrial. Quizás, una de las fallas del segundo paradigma radique en que se encuentra atado a la crítica del primero. Así, ambos modelos quedan atenidos a las implicaciones normativas del funcionamiento social $\mathrm{y}$, por tanto, a la cuestión de si basta con garantizar la autonomía privada mediante derechos de libertad o si — para que se produzca tal autonomía — ha de quedar asegurado el otorgamiento de derechos relativos a prestaciones sociales. Según lo sugiere este autor, ambos puntos de vista dejan de lado la interna conexión entre autonomía privada y autonomía ciudadana. Y por tanto, el sentido democrático de la organización de una comunidad jurídica. En definitiva, más allá de los presupuestos fácticos del status de personas jurídicas, debería considerarse también que los ciudadanos serán autónomos en la medida en que puedan verse a sí mismos como autores del Derecho al que están sometidos como destinatarios. ${ }^{37}$

Las críticas apoyadas en la insensibilidad hacia la afectación de la autonomía, derivada del funcionamiento del propio aparato administrativo, han sido identificadas como el problema del paternalismo del Estado social. ${ }^{38} \mathrm{Y}$ a propósito de éste se ha suscitado la cuestión de si dicho paradigma es compatible con el principio de libertad jurídica. Es decir, si sus medidas logran el perseguido restablecimiento de la autonomía o si, pese a sus intenciones provoca lo contrario. Entonces, frente a los déficits de ambos modelos, se impone pensar en alternativas posibles. ${ }^{39}$

El paradigma que sea superador del Estado de Bienestar habrá de estar guiado igualmente por la intención de controlar los efectos indeseados del sistema económico capitalista. Su vocación consistirá en reestructurarlo — social y ecológicamente— de un modo que refrene el

36 Habermas, J., Facticidad y Validez..., cit., p 471. Se respeta la terminología empleada por el autor.

37 La autonomía de los ciudadanos y la legitimidad del Derecho, remiten la una a la otra. En las condiciones de una comprensión posmetafísica del mundo, sólo podría considerarse legítimo al Derecho que surge de la formación discursiva de la opinión y la voluntad de ciudadanos dotados de unos mismos derechos. Un orden jurídico es legítimo, entonces, en la medida en que asegura la autonomía privada y la autonomía ciudadana de sus destinatarios. Al mismo tiempo, debe su legitimidad a las formas de comunicación en las que esa autonomía puede expresarse y acreditarse. Habermas, Facticidad y validez..., cit., pp 490-2.

38 En cuanto éste resulta insensible a las secuelas restrictivas de la libertad que derivan de su obrar compensatorio.

39 Se ha de asumir que: i) está cerrado el camino de retorno que el neoliberalismo propugna, ii) se busca el redescubrimiento del individuo por el riesgo de que el Estado social amenace lo que es su objetivo declarado: el restablecimiento de la autonomía privada, iii) no se trata de interrumpir el desarrollo del Estado de Bienestar, ni ratificarse en él, sino continuar en un plano de reflexión superior. Habermas, J., Facticidad y Validez... cit, p 492. 
empleo del poder administrativo, reconectándolo con el poder comunicativo e inmunizándolo así contra el poder ilegítimo. ${ }^{40}$ En tal sentido, el orden jurídico será legítimo en tanto asegure la autonomía "privada" y la "ciudadana", en términos de Habermas. Y esto se puede lograr a partir de las formas de comunicación en que tal autonomía se expresa y acredita.

Este paradigma se configuraría como un "paradigma procedimental del Derecho". ${ }^{41} \mathrm{Y}$ por tal carácter formal no permite saber a priori cómo sería una sociedad buena. Sin embargo, sí permite saber que ella es incompatible con una sociedad que albergue grandes disparidades de género en lo referente a status, poder y seguridad económica. Que no será tal una sociedad que limite la libertad reproductiva de las mujeres o tolere altos niveles de pobreza, violencia e injusticia racial o estructure sus puestos de trabajo sin atender a las necesidades de una familia. Menos, una sociedad que niegue a muchos de sus miembros las facultades y el poder necesarios para hacerse con las riendas de su propia existencia diaria. ${ }^{42} \mathrm{Ni}$ tampoco, una sociedad que no reconozca la presencia de pueblos originarios y sus derechos.

En tren de configurar este nuevo paradigma, cabe volver sobre la crítica a su antecesor. Se ha señalado que resulta problemático que el paradigma del Estado de bienestar deje de lado la garantía de libertad que hace a la legitimidad del Derecho. En cambio, tal como lo propone Habermas, la idea de una sociedad justa lleva aparejada la promesa de emancipación y dignidad humanas. En tal sentido, la justa distribución de las compensaciones sociales no puede sino ser el resultado del sentido universalista del Derecho. La garantía de éste se debe concentrar en asegurar la libertad e integralidad de cada uno. ${ }^{43}$

Por ello, injusticia será la coartación de la libertad y vulneración de la dignidad humana. Entonces, la justicia social debería referirse no solamente a la distribución de bienes, sino también a las condiciones institucionales necesarias para el desarrollo y ejercicio de las capacidades individuales y de la comunicación y cooperación colectivas. Esto se vuelve más evidente en la discusión feminista del Derecho. El feminismo insiste en el sentido emancipador de un trato jurídico igual porque se endereza contra estructuras de dependencia que el paradigma distributivo del Estado de bienestar no hace sino ocultar. La dominación consiste en condiciones institucionales que impiden a las personas participar en la determinación de sus acciones o en las condiciones de sus acciones. La política de la discriminación positiva, por bien intencionada que sea, reprime las voces de quienes serían las únicas que podrían decir qué es lo que en cada caso pueden contar como razones relevantes en lo que respecta a un trato igual o desigual. ${ }^{44}$

40 Ídem

41 No se trata de un paradigma formal porque carezca de contenido sino porque se limita a señalar condiciones necesarias bajo las que los sujetos jurídicos, en su rol de ciudadanos, pueden entenderse entre sí, sobre cuáles son sus problemas y cómo deben ser resueltos. Este paradigma lleva implícita la participación no sólo de las elites que manejan el Derecho como expertos, sino también la incorporación en dicha práctica de todos los implicados. En el núcleo de este paradigma se conserva la idea de la autonomía, en el sentido en que los hombres y mujeres sólo pueden actuar como sujetos libres en la medida en que obedezcan a leyes que ellos mismos se hayan dado, conforme a las convicciones alcanzadas intersubjetivamente. Habermas, Facticidad $y$ validez..., cit., pp 531-2.

42 Rhode, D. I. Justice and gender, Cambridge, Massachusetts, 1989, p 317, citado en Habermas, Facticidad y validez..., cit., p 512.

43 Dice Habermas: "en una comunidad juridica nadie es libre mientras la libertad de unos haya de pagarse al precio de la opresión de los otros", Ibidem, p502.

44 Y esto es lo que muestra la relevancia de la participación discursiva de los o las interesadas en la definición de sus propios intereses. Participación que como se sostiene resulta fundamental para dar legitimidad sustantiva a las 
En este sentido, el paradigma propuesto como superador asumiría la complejidad actual de las sociedades, volviendo visible la idea de la autonomía de la comunidad jurídica, integrada por miembros iguales y libres. ${ }^{45}$ Siguiendo esta línea de argumentos, la teoría discursiva entiende que el Estado democrático de Derecho resulta de la institucionalización del Derecho legítimo a través de procedimientos y presupuestos comunicativos. Estos últimos son los que garantizan la formación discursiva de la opinión y la voluntad, haciendo posible el ejercicio de la autonomía política y una producción legítima de normas.

Asimismo, se ha destacado que podría evadirse el problema del paternalismo del Estado Social a través de la judicialización de los derechos sociales. Esto es, la reclamación de los derechos por parte de los propios titulares en ocasión de su violación. Sin embargo, esto último no puede ser comprendido con desapego de las dificultades para el acceso a la justicia y al goce de los derechos en general. Por eso, la finalidad igualadora de los DESC impone no sólo una política de protección compensatoria que refuerce el conocimiento jurídico para facilitar tal acceso a la justicia, sino también una colectivización de la imposición del Derecho. ${ }^{46}$

En todo caso, no se puede dejar de advertir que desde la señalada óptica procedimental del Derecho, al Poder Judicial le cabe proceder a través de un "discursos de aplicación" del Derecho. En ellos, se habrán de articular las razones contenidas en la ley formada a partir de los referidos procedimientos comunicativos. Sin embargo, en la medida en que las leyes dejen un margen librado a la concretización y el Poder Judicial deba desarrollar su actividad en una "zona gris" —entre la producción legislativa y la aplicación del Derecho — se verá obligado a complementar los "discursos de aplicación" con elementos tomados de los "discursos de fundamentación". Y en este sentido, se impone la carga de una mayor legitimación de su obrar. Carga que podría quedar satisfecha obligando a la justicia a dar justificación ante un foro ampliado de críticos de ella ${ }^{47}$ o elevando los estándares de justificación como si realmente los jueces debieran dirigirse a un "auditorio universal", considerado éste como un ideal regulativo. ${ }^{48}$

Por otro lado, y si bien resulta deseable la mayor participación de los interesados en los procedimientos administrativos, ésta no debe ser vista como sucedánea de la protección jurídica. Así es que no debe considerarse superfluo el control reactivo a que esté sometida la Administración. Sin perjuicio de complementarlo además con la ampliación de la reserva de ley, la dinamización de la protección de los derechos fundamentales y la formas colectivas de protección jurídica. Con ello se impone mantener un proceso abierto y persistente de diálogo colectivo, para lo cual resulta esencial la formación ciudadana y el estímulo a la participación

previsiones protectorias del Derecho. De hecho, con el crecimiento y el cambio cualitativo de las tareas estatales se refuerza la necesidad de su legitimación. Así, "cuanto más se recurre al Derecho como medio de regulación y control politicos y de configuración social, tanto mayor es la carga de la legitimación que la génesis democrática del derecho ha de soportar. "Cfr. Habermas, Facticidady Validez..., cit., p 513.

45 Ibidem, p 475.

46 Asimismo, se destaca que la realización de demandas a través de asociaciones o figuras como la del Defensor del Pueblo, sólo podrían neutralizar la debilidad de los ciudadanos si tal protección no se limitase a la actuación de una representación jurídica. Para cumplir con su finalidad emancipadora, esta forma asociativa de reclamar los derechos debiera implicar a los individuos en la construcción y gestión de sus propios intereses, como parte de un proceso político de realización del Derecho. Todo ello según Habermas, Facticidad y validez..., cit., p 494.

47 Ibidem, p525.

48 En el sentido dado a éste por Perelman, Ch. - Olbrechts-Tyteca, L., en: Tratado de la argumentación. La nueva retórica, Gredos, Madrid, 1989. 
deliberativa. Todo esto como forma de buscar la autoridad en el resultado de una siempre inacabada y conflictiva conversación colectiva. ${ }^{49}$

\section{Algunas conclusiones}

Como hemos visto, los derechos sociales han operado disruptivamente dentro del ordenamiento jurídico construido a la imagen y semejanza de las garantías propias del Estado decimonónico. La incorporación de estos derechos, conforme la mutación del rol del Estado, impuso algunas modificaciones en el funcionamiento del Derecho, las que sin embargo aun se muestran inacabadas.

Sumado a ello, se debe considerar que el propio Estado de bienestar hoy se encuentra en crisis - financiera y de legitimación — por lo cual se impone revisar las posibilidades para una salida superadora que evite el retroceso hacia formas mínimas de Estado que sólo consagrarían los desequilibrios que otrora se quiso evitar.

En la propuesta de Habermas, hemos visto la importancia de iniciar un tránsito hacia formas participativas y deliberativas como un camino hacia la mayor legitimidad del Derecho que se aplica a ciudadanas y ciudadanos. En este sentido, resulta interesante repensar las formas de los derechos sociales —en cuanto mandatos de optimización - y la utilidad del proceso judicial como espacio de discusión que permita el control del obrar de los poderes políticos. La reformulación de estos derechos habilita el control judicial de razonabilidad de las políticas públicas (o su ausencia absoluta) en un ejercicio legítimo de la función jurisdiccional. Por su parte, la dimensión colectiva de los derechos sociales justifica la participación de dichos grupos interesados en el proceso judicial, como una forma de concreción del cambio de paradigma, orientado hacia formas participativas de elaboración del Derecho.

Estamos aun hoy en los albores de una nueva comprensión del Derecho. La teoría ha demorado bastante pero la práctica constitucional no la ha esperado y se ha expandido en formas de Litigio de Interés Público que han intentado el cambio social y también, el freno del cambio climático, impulsando medidas concretas para ello. Principiar por entender a los derechos sociales en el marco del Estado social, nos prepara para poder hacer frente a estas nuevas y urgentes formas de litigio. Con esta contribución me propuse ilustrar algunas aristas que permiten una mejor comprensión de los derechos sociales en el marco del Estado social, como una manera de contribuir a la mejor comprensión acerca del Derecho contemporáneo y sus mutaciones.

\section{Bibliografía}

Briggs, Asa, The Welfare State in historical perspective, European Journal of Sociology / Archives Européennes de Sociologie, Volume 2, Issue 2, December 1961 , pp. 221 - 258.

Castel, Robert, La metamorfosis de la cuestión social. Una crónica del salariado, Paidós, Buenos Aires, 1997, pp281-2.

49 Gargarella, Roberto, La sala de máquinas de la Constitución..., cit., pp 365-366. 
Esping-Andersen, Gøsta, The three worlds of welfare capitalism, Cambridge: Polity Press, pp 9-54, 1990.

Ewald, François, A concept of Social Law en Dilemmas of Law in the Welfare State, Teubner, Gunther (Ed.), Walter de Gruyter, Berlin, New York, 1986, pp 40-75.

Ferrajoli, Luigi, Ferrajoli, Luigi, Derechos y garantías. La ley del más débil, $7^{\circ}$ edición, Trotta, Madrid, 2010.

Gargarella, Roberto, La sala de máquinas de la Constitución. Dos siglos de constitucionalismo en América Latina (1810-2010), Katz, Buenos Aires, 2014, pp 199-203.

Grimm, D., Constitucionalismo y derechos fundamentales, Editorial Trotta, Madrid, 2006.

Grimm, D., Constitucionalismo y derechos fundamentales, Editorial Trotta, Madrid, 2006, p 188.

Habermas, J., Facticidad y Validez. Sobre el derecho y el Estado democrático de derecho en términos de teoría del discurso, $4^{\circ}$ Edición, Trotta, Madrid, 2005

Habermas, Jürgen, Law as Medium and Law as Institution, en Teubner, Gunther (Ed.), Dilemmas of Law in the Welfare State, Walter de Gruyter, Berlin, New York, 1986, pp 203-220.

Muller, Pierre, Génesis y fundamento del análisis de politicas públicas, INNOVAR, Revista de Ciencias Administrativas y Sociales, N 11, Enero - Junio de 1998, pp99-109 (p 100).

Offe, Claus, Some contradictions of the modern Welfare State, en Contradictions of the Welfare State, Contemporary politics, London, 1984 (pp 147-161) p.147.

Offe, Claus, Un diseño no productivista para las políticas sociales, en Contra la exclusión. La propuesta del ingreso ciudadano, Miño y Dávila Editores, $2^{\circ}$ edición, Buenos Aires, 2004, pp 80-105.

Perelman, Ch. - Olbrechts-Tyteca, L., en: Tratado de la argumentación. La nueva retórica, Gredos, Madrid, 1989.

Rhode, D. I. Justice and gender, Cambridge, Massachusetts, 1989, p 317, citado en Habermas, Facticidad y validez..., cit., p 512.

Ucín, María Carlota, Juicio a la desigualdad. La defensa de los derechos sociales a través del proceso, Marcial Pons, Madrid, 2021.

Valenti Nigrini, G. - Flores Llanos, U., Ciencias sociales y politicas públicas, en Revista Mexicana de Sociología, Vol. 17, Dic. 2009, pp 167-191 (pp 174-175). 